\title{
Study of Communication and Interaction of Management members with Members SAE Pujon Cooperative of Malang Regency, Indonesia
}

\author{
Bambang Sigit Pramono, Samsul Wahidin and Praptining Sukowati
}

University of Merdeka Malang, Indonesia

Corresponding Author: Tommy Hariyanto

\begin{abstract}
This study focuses on the SAE Pujon Cooperative Communication with the aim of knowing the use of communication symbols or symbols in the interaction process. To see the process of interaction between the Management, which in this case is the Chairman of the Cooperative, with employees or members, is carried out with a qualitative approach with participatory observation, in order to directly observe symptoms related to the use or use of verbal and non-verbal communication symbols or symbols, Indepth interviews were also conducted to explore and understand more deeply the meaning of symbols or symbols of their interaction process, guided by the statements in the research objectives, namely analyzing and describing the communication between the committee and members of the SAE Pujon Cooperative, Malang Regency. East Java Province and analyzes and describes the inhibiting and supporting factors of communication and interaction between the management (Ketrua) and members of the SAE Pujon Cooperative, Malang Regency, East Java Province. The results showed that the process of interaction or communication between the Management (Chairperson) and employees as well as members who use verbal and non-verbal symbols or symbols can be seen when the Chairman of the Cooperative gives "orders", "prohibitions", and "advice" to employees and members. Likewise, members' perceptions of the use of the symbol or communication symbol used by the Chairman of the Cooperative. In giving orders, prohibitions and advice, the symbol or symbol of verbal communication used is Nyuwun tulung (asking for help), do not and don't even insist (don't be like that). Meanwhile, the non-verbal symbols or symbols used are moving the pen back and forth many times, moving the pen left and right and shaking the head, sitting back and not leaning, the clothes worn and other symbols of success. Members' perceptions of the symbol or communication symbol used by the Management (Chair) in interacting are very positive, it can be seen from the daily lives of cooperative members according to what the Chairman of the Cooperative says. Efforts to legitimize symbols or symbols with the values of the cooperative community, also aim to build an impression (image) to the community, that the symbols used by the cooperative are symbols that do not conflict with social values of society. In fact, it is said that the content of these symbols or symbols complement and co-exist with the social values of society. Furthermore, a compromise attitude towards the Cooperative movement creates a new atmosphere in symbols, meaning that these symbols are given a rational nuance, with the hope that the function of the symbol or symbol will gain legitimacy from the Cooperative community, with the aim that these symbols can survive in practice. -practices of life in the cooperative community.
\end{abstract}

Keywords: Communication, Cooperative Members, Social Interaction Theory, Symbolic Interactionism Theory.

\section{INTRODUCTION}

Something interesting in social life and happened throughout the history of the establishment of cooperatives in the province of East Java. Where a cooperative is able to make the people who live in the sub-district depend on the existence of this cooperative. When this cooperative stops its service activities, the economic wheels of most of the community will also be disrupted. What is unique is that a conflict in the community will be resolved peacefully in a friendly manner by simply conveying the sentence "seduluran selawase". Is the SAE Pujon Cooperative in Pujon sub-district, Malang district, East Java province.

A total of 8,776 (eight thousand seven hundred and seventy-six) members of the SAE Pujon cooperative, generate a turnover of money in the region of 75.1 billion in a year. Is one of the assets owned by the Pujon community from a cooperative activity. From the point of view of communication, of course there are things that cause the trust of cooperative members to improve so that economic growth will get better too. The communication process carried out by the managers of the SAE Pujon header is the key to maintaining that trust.

In particular, a cooperative organization, such as metamorphosis, strives to be a good business entity by communicating inside and outside the institution openly, honestly and clearly. The community, especially cooperative members, understands that the success achieved depends on the ability of managers, managers, employees and members to communicate effectively. 
Communication is the process of sending and receiving messages. Meanwhile, effective communication occurs when individuals reach the same understanding, stimulate other parties to take action, and encourage people to think in new ways.

As an organization, Kop SAE Pujon is also protected under Government Regulation number 17 of 1994 concerning the Dismissal of Cooperatives by the Government and strengthened by Regulation of the Minister of Cooperatives and UKM RI number 10 of 2015 concerning Cooperative Institutions. Guided by this regulation, the SAE Pujon Cooperative is able to survive and continue to grow to serve its members.

The Pujon community is likened to a cooperative minded citizen. His daily mindset cannot be separated from the meaning of SAE Pujon's cuphead, which continues to learn to improve the economy. Every step of his life is associated with cooperatives. Of course there are things that connect the interests of the community itself with cooperative institutions as economic organizations in Pujon, so that good communication and mutual trust are established.

The ability to communicate effectively will increase productivity, both individual organizations can anticipate problems, make decisions, coordinate workflows, develop relationships, and promote products and services. Make an impression on colleagues, employees, supervisors and customers. Also feel and fulfill the needs of all interested parties. Communication skills, determine success, wherever we are, whether for virtual companies such as metamorphosis, opening their own business, investing in one company, buying or selling products in competition, winning business competition.

The key to success in business competition lies in the ability of each company to win the market. On the basis of this statement emerged the concept of Marketing Communication. Marketing communication has become the main focus, and efforts to improve it are the most serious challenges that must be carried out in all business sectors in improving the quality of their business. Quality is often translated as a relative measure of the "goodness" of a product or service. The goodness of these services is usually measured from the design aspect of the design aspect and the aspect of its suitability. The design aspect is a function of the defined quality specifications. To be able to achieve the satisfaction of cooperative members in order to feel more served, it does not only depend on the quality of the product it provides, but also depends on how the communication process is.

Kotler (1995: 87) describes satisfaction as the level of feelings a person has after comparing the perceived performance (or results) with previous expectations.[1]. Basically, the satisfaction of cooperative members feeling well served can be divided into three levels, namely disappointed, satisfied and very satisfied. Disappointed, occurs when the performance is below expectations, while satisfied and very satisfied is achieved if the performance of each matches and exceeds expectations. In the context of measuring the dimensions of service quality (service), Parasuraman, Zeithami, and Berry (1998: 101) explain that the measure of service quality consists of 22 variables [2]. Furthermore, all these variables after going through various studies are grouped into five dimensions, namely direct evidence (tangibles), state (realiability), responsiveness (responsiveveness), assurance (assurance), and attention (empathy).

Therefore, it is not only one dimension that affects consumer satisfaction, it is also expanded which dimension has the most dominant influence on customer satisfaction, so that it needs to get top priority in determining its marketing strategy. It is hoped that this strategy will be in line and in line (fit) with the marketing activities carried out. All of that is inseparable from the role of the management, in this case the Chairman of the Cooperative who is a leadership figure of the Cooperative institution and is considered the most dominant and plays a decisive role in the process of developing the cooperative business. Even in the current period, the Heads of Cooperatives have shown their influence / vitality in leadership that is close to the community and prominent in meeting the moral and economic needs of the community.

The community, especially cooperative members, hopes that a cooperative chairman can help solve economic problems practically according to the needs of members. With his superior knowledge of cooperatives, he is often seen as someone who can always understand the economic needs of his members. From here the author tries to dig deeper into the interactions that occur in the cooperative and the use of a symbol or communication symbol by the chairman of the cooperative in order to develop the organization, business and marketing for members and the community around the cooperative. This marketing dimension seems to apply to almost all types of organizations, both profit oriented and non-profit organizations, such as government agencies or social communities with their social marketing. This of course applies to organizations that are quasi profit oriented, such as hospitals. With the increasing number of cooperatives operating, there is a tendency for increasingly fierce competition between cooperatives in their efforts to raise funds from the community. This competition will be evident in the cooperative's efforts to raise funds through savings. With various forms of savings, the Cooperative provides facilities and convenience to its members. This results in more and more alternatives for members to choose the type of savings, and the possibility of members switching to other cooperatives is also getting bigger. As a service provider institution, cooperatives provide basic services in the form of security (trust) accompanied by additional goods and services, for example employee tidiness, member service rooms. 


\section{LITERATURE REVIEW}

\subsection{Communication Theory}

Talking about communication problems, it can be said that most of human life from birth to death is for communication activities. Narrowly, the definition of communication can be defined as a message sent by someone to one or more recipients with a conscious intention to influence the behavior of the recipient (Supratiknya, 1997: 30) [3]. Thus the communication process takes place is a process of activities carried out consciously, meaning that to form an effective communication network, the sender of the message or in this case the "communicator" does consciously with a specific purpose to the recipient of the "communicant" message.

In the communication process, non-verbal communication usually takes place immediately, so that the nature of non-verbal communication is still in an "interpersonal" communication system. Thus the use of symbols or symbols in the communication process must be able to bridge the interests of the communicator (Chairman of the Cooperative) with the communicant (employees and members), this is intended to establish effective communication.

Communication is the basis of all human beings. Because without communication, human interaction will not occur. Most of the interactions between humans take place in situations of inter-communication (Widjaja, 2000: 120) [4]. Interpersonal communication or interpersonal communication is communication carried out directly or face to face between the communicator and the communicant.

\subsection{Symbol Theory}

When a plural society interacts with other societies of different cultures, when the communication process is carried out verbal and non-verbal symbols are indirectly used in the process. The use of these symbols often produces different meanings from the actors of the communication, although rarely the meaning of symbols will produce the same meaning as the actors of the communication expect. Piere defines symbols as signs that refer to the object itself, involving three basic elements in the triangle theory of meaning: the symbol itself is one or more references and the relationship between symbols and references (Sobur, 2003: 156) [5]. Here it can be seen that the relationship between a symbol and a marker and something that is signified (sign) is conventional. Based on the conversion, Alex Sobur (2003: 156) explained that the wearer community interpreted the characteristics of the relationship between the symbol and the object referred to and interpreted its meaning [5]. In this study, the symbols used in the management's communication with SAE Pujon header members can be interpreted by the members, referring to the object to be interpreted as meaning.

\subsection{Symbolic Interactionism Theory}

Communication in the perspective of symbolic interaction is described as the formation of meaning (interpretation of messages or other people's behavior) by communication participants. Some important concepts in the perspective of symbolic interaction are self, other self, symbols, meaning, interpretation and actions. Communication participants are active, reflective and creative, interpreting, predicting complex and difficult to predict behavior (Mulyana, 2005: 160) [6].

Herbert Blumer suggests the type of premise that underlies the symbolic interaction communication model. First, humans act on the basis of the meaning given by individuals to their social environment (verbal symbols, non-verbal symbols, physical environment). Second, meaning is directly related to the social interactions that individuals carry out with their social environment. Third, meanings are created, maintained and changed through an interpretive process carried out by individuals in relation to their social environment (Mulyana, 2005: 160) [6].

\subsection{Social Interaction Theory}

Definition of Social Interaction According to Homans (in Ali, 2004: 87) defines interaction as an event when an activity carried out by one person against another individual is rewarded or punished by using an action by another individual who is his partner [7]. The concept put forward by Homans implies that interaction is an action taken by a person in an interaction which is a stimulus for the actions of other individuals who are partners. The definition of social interaction according to Bonner (in Ali, 2004) is a relationship between two or more individuals, where individual behavior affects, changes or influences other individuals or vice versa [7].

\section{RESEARCH METHODS}

\subsection{Research Type}

This type of research is a taxonomical study in the form of a descriptive case study. Research does not test hypothetical theories but looks for new knowledge, combines and interprets it to get a unity of interpretation (Rakhmat, 1993: 26) [8]. Through this method it is possible to find subjective or formal theories (Moleong, 1998: 87) [9]. The research approach and strategy chosen 
in this research process is the qualitative research approach and the Grounded Theory research analyst strategy developed by Strauss and Corbin, which is to examine more deeply the social phenomenon of "changes in attitudes and behavior". In studying the phenomenon of social change in society, actually can research using a quantitative perspective (ethical perspective) or a qualitative perspective (emic perspective), or also converge the two perspectives. This research will use a qualitative approach (emic perspective).

\subsection{Research focus}

The objects of research are those related to the symbol of communication, both the symbol of verbal communication and the symbol of non-verbal communication, in the interaction between the Management (Chairman) and the manager of the cooperative with employees and members as well as between members themselves.

1) Analyze and describe the Communication of the Management (Chair) with SAE Pujon Kop Members with Indicators:

a. Communication standards (Incoding process, transmission media, decoding, response and feedback).

b. Interaction as an event / communication process (personal interaction, social interaction and organizational interaction).

c. Symbolic interaction of the administrator / chairman, and manager / manager, with members (verbal symbols and nonverbal symbols)

2) Analyze and describe the inhibiting and supporting factors in the communication of the Management (Chair) and the Manager with SAE Pujon Kop members, with indicators:

a. Internal Inhibiting Factors Affecting Management Interaction with Members.

b. External Inhibiting Factors Affecting Management's Interaction with Members.

c. Internal Supporting Factors Affecting Management's Interaction with Members.

d. External Supporting Factors Affecting Management Interaction with Members.

(1) Social Change, External Support in Pujon District Community With the Presence of the Pujon SAE Cooperative.

(2) External Supporters, Public Opinion About the Existence of the SAE Pujon Cooperative.

\subsection{Data analysis techniques}

Data in "qualitative" research is always in the form of a series of words, not a series of numbers. The data analysis process in this study consisted of three activities carried out simultaneously, namely data reduction, data presentation and drawing conclusions or verification.

a. Data collection that appears in the form of words and not numbers is collected through various means such as observation, interviews, document digest, tape, recordings are usually processed through recording, typing, editing, or writing (Miles and Huberman, 1992: 15) 10].

b. Data reduction is the process of selecting, focusing on simplifying, abstracting and transforming raw data that emerge from written records in the field. Qualitative data is simplified and transformed in a variety of ways, including strict selection, summaries or brief descriptions, categorization in a broader pattern, sometimes even changing in numbers or rankings, for example, researchers categorize research areas into high or medium levels. This does not mean quantitative data. The strategy used according to Miles and Hubermas is to use the words to describe the numbers, so that they exist together in the next analysis (Miles and Hubermas, 1992: 16-19) [10].

c. Data presentation is an arrangement of a collection of information that allows drawing conclusions and taking action. The old method is in the form of narrative text so it can take thousands of pages and it is difficult to draw conclusions. Researchers try to use a new method, which uses text magtriks, graphics, networks and charts in addition to narrative text. Qualitative data analysis begins by looking for the meaning of things, noting regularities, patterns, explanations, possible configurations, causal pathways and propositions. Researchers will draw conclusions loosely, remain open and skittish but then tie them into more detail and firmly rooted.

d. These conclusions were verified during the verification research process in the form of a review or rethinking of field notes, which may have been fleeting or even carried out carefully and took a long time, as well as brainstorming thoroughly to develop inter-subjective matters. The meanings that emerge from the data must be tested for their validity, robustness and suitability, so as to form their validity (Miles and Hubermas, 1992: 19) [10]. 


\section{DISCUSSION}

\subsection{Communication of Management / Chairperson and Management with Kperasi SAE Pujon Members}

Communication is a prerequisite for human life because without communication, interaction between humans, whether individually, in groups or organizations, would not be possible. Communication is a process by which a person or several people, groups, organizations and communities create and use information to connect with the environment and other people. According to Fajar (2009: 60) in his book entitled communication science, communication theory and practice also aims at changing behavior, changing opinions, changing attitudes, and social changes [11]. There are three basic functions that cause why humans need to communicate according to Cangara (2006: 3) in an introductory book on communication. First, the human desire to control the environment [12].

Through communication, humans can find out the opportunities that exist to be exploited, maintained and avoid things that threaten the natural surroundings. There are three basic functions that cause why humans need to communicate according to Cangara (2006: 3) in an introductory book on communication. First, there is a human desire to control the environment. Through communication, humans can find out the opportunities that exist to be exploited, maintained and avoid things that threaten the natural surroundings [12].

Through communication, humans can find out about an event and can even develop their knowledge, namely learning from their experiences and the information they receive from their surroundings. Second, there is human effort to adapt to their environment. The process of continuing a society actually depends on how society adapts to its environment. Third, there are efforts to transform the legacy of socialization. A society that wants to maintain its existence, members of the community are required to exchange values, behavior and roles. For example, how parents teach their children manners, how schools are functioned to educate citizens, and how the government uses the policies it makes to protect the interests of the community members it serves.

Actions of communication can be done in various ways, both verbally and nonverbally. Communication can also be done directly and indirectly. According to Stewart L Tubbs and Sylvia Moos as quoted by Marhaeni Fajar (2009: 8) in a communication science book, the theory and practice of effective communication can have an effect on others, which is also called persuasive communication which in its implementation requires an understanding of the factors -factors on the communicator and the message that has an effect on the communicant [11]. Generating real action is indeed the most important indicator of effectiveness because to cause action, we must first succeed in instilling understanding, forming and changing attitudes or fostering good relationships, besides that it can also influence human behavior.

One way to instill understanding and change attitudes is through socialization. In the socialization process in general, a number of messages will be conveyed to the communicant, in the hope that the communicant will understand the message and usually aims to influence and even change attitudes.

\subsection{Inhibiting and supporting factors in the communication of the Management (Chair) and Management with SAE Pujon Kop members}

\subsubsection{Internal Inhibiting Factors Affecting Management Interaction with Members.}

1) Feelings of Stress

From the results of an interview on 31 September 2019 with Pak Siyar's family, Sebaluh village, it was found that in managing his dairy business, he felt stressed and hopeless. This is due to the fact that his cows cannot produce fresh milk according to the milk production standards for each cow. While the debt to the cooperative has not been able to pay it off either. He feels insecure when he hears of the success of fellow cow breeders in his village to be able to produce fresh milk up to 24 liters per day per cow.

2) Aspects of Stress

There are two aspects of stress according to Sarafino (1997), namely [13]:

a. Biological Aspects

The biological aspect of stress is physical. Physical symptoms of stress experienced by individuals include: headaches, nervousness, tension muscles, sleep disorders, indigestion, eating disorders, skin disorders and excessive sweat production.

b. Psychological Aspects

The psychological aspect of stress is in the form of psychological symptoms. Psychic symptoms of stress include:

(1) Emotional symptoms 
Stress conditions can disrupt individual emotional stability. Individuals who experience stress will show symptoms of feeling sad, irritable, excessive anxiety about everything, and depression

(2) Cognitive symptoms

Stressful conditions can interfere with individual thought processes. Individuals who experience stress tend to experience decreased memory problems, weakness in solving problems, fear of failure, impaired attention and concentration

(3) Behavioral symptoms

Stress conditions can affect daily behavior which tends to be negative, causing problems in interpersonal relationships, such as withdrawing from family, loss of interest, explosive emotions, and aggression.

\subsubsection{External Inhibiting Factors Affecting Management's Interaction with Members.}

1) Communication barrier

Communication barriers are all forms of disturbance that occur in the process of delivering and receiving a message from an individual to another individual caused by environmental factors as well as physical and psychological factors from the individual himself.

2) Inhibiting Components in Communication

According to Fajar (2009), there are several obstacles in communication, namely [11]:

a. Obstacles from the sender of the message, for example the message to be conveyed is not clear to himself or the sender of the message, this is influenced by feelings or emotional situations that affect motivation, namely encouraging someone to act according to their wishes, needs or interests.

b. Barriers to encoding / symbols. This can occur because the language used is not clear so that it has more than one meaning, the symbols used between the sender and the recipient are not the same or the language used is too difficult.

c. Media barriers are obstacles that occur in the use of communication media, such as radio interference so that they cannot hear messages clearly.

d. Barriers in password language. Obstacles occur in interpreting the code by the recipient.

e. The resistance of the message recipient. For example, lack of attention when receiving / listening to messages, prejudice and incorrect responses and not seeking further information.

3) Inhibiting Factors in Communication

Wursanto (2005) summarizes that communication barriers consist of four types, namely [14]:

a. Barriers of a technical nature

Technical barriers are obstacles caused by various factors, such as:

(1) Lack of facilities and infrastructure needed in the communication process

(2) Mastery of inappropriate communication techniques and methods

(3) Physical conditions that do not allow the communication process to occur which are divided into human physical conditions, physical conditions related to time or situation / circumstances, and equipment conditions

b. Ecological / Physical Barriers

Based on the information obtained by researchers from key informants. The communication process is usually disrupted due to environmental factors, both related to noise and weather, especially during the rainy season. During the rainy season, usually people who are targeted to be present in the Family Planning program tend to be lazy to attend socialization and counseling activities, the reason is that it rains so that the women wait for the rain to stop first, even if the rain has been falling for a long time but it doesn't stop, usually mothers automatically discourage attending.

c. Anthropological / semantic barriers

Barriers caused by errors in interpretation, errors in providing understanding of the language (words, sentences, codes) used in the communication process. If sociological-anthropological-psychological barriers exist on the part of the communicant, then the semantic barrier lies with the communicator. The semantic factor concerns the language used by the communicator as a "tool" to channel thoughts and feelings to the communicant. For the sake of smooth communication, a 
communicator must really pay attention to this semantic disturbance, because wrong words or writing can lead to misunderstanding (misunderstanding) or misinterpretation (misinterpretation) which in turn can lead to miscommunication (miscommunication).

\section{d. Behavioral barriers}

Barriers to behavior are also called humanitarian barriers. Barriers caused by various forms of attitudes or behavior, both from communicators and communicants. Behavioral barriers appear in many forms.

\subsubsection{Internal Supporting Factors Affecting Management's Interaction with Members.}

Interpersonal communication that can be said to be effective is very important for members of the organization which can be expected to produce exchange results in information and mutual understanding of one another (Mutual Understanding). The effectiveness of interpersonal communication according to the humanistic viewpoint (Devito, 2011) [15]. contains the following elements:

1) Openness (openess)The quality of openness has a reference point of at least three points of view from interpersonal communication. First, effective interpersonal communicators are very honest with the individuals they are communicating with. Cases like this do not mean that the individual should immediately describe all his life history. The second aspect of openness, refers to the communicator to always communicate honestly with all stimuli that come to the individual. Silent and uncritical individuals who are also not responsive generally form mixed conversation participants. We want people to always actively react openly and honestly to whatever we say. The third aspect concerns the aspects of ownership of feelings and thoughts.

2) Empathy, is the ability of an individual to be able to understand what is being experienced by another individual at a certain time. Sympathy in other words is feeling for another individual or you can feel sadness which is different from empathy, empathy is feeling something that other individuals also feel exactly the same.

3) Supportiveness, a very effective interpersonal communication relationship, namely a relationship where there is an attitude of mutual support for one another. Honest and empathetic communication cannot always take place in a supportive environment. We show how supportive attitudes are with descriptive not evaluative thinking.

4) Equality (Equality),in all situations, there may often be inequality or injustice. One individual may feel smarter, and the other individual is richer, more handsome or beautiful, and bigger than the other individual. Rarely have there ever been two individuals who were truly equal in all respects. Out of this inequality, interpersonal communication can be more effective if the atmosphere is equal. In other words, there must be tacit recognition if both parties are equally valuable and valuable and also both parties have something very important and are required to contribute.

\subsubsection{External Supporting Factors Affecting Management Interaction with Members.}

The sympathy that arose in the community and members of the SAE Pujon cooperative in particular, for the leadership in cooperative management by Mr. Abdi Suwasono and other management, did not appear suddenly. There is a previous process that makes the interaction so good, of course, there are many considerations. Theoretically, Homans (in Ali, 2004: 87) defines interaction as an event when an activity carried out by one person against another individual is rewarded or punished by using an action by another individual who is his partner. The concept put forward by Homans implies that interaction is an action taken by a person in an interaction which is a stimulus for the actions of other individuals who are partners [7].

Meanwhile, other external factors that influence the interaction between the management and SAE Pujon Kop members include:

1) Sympathy, is a process of someone feeling attracted to other people. Feelings of sympathy from the community / farmer members of the SAE Pujon cooperative are awakened by the success of the farmer members who are their neighbors when interacting. Things like that can also be conveyed to a person or group of people or a formal institution at special times. An example of sympathy is giving a gift to a member of a dairy farmer for achieving an achievement;

2) Motivation, is the encouragement, stimulation, influence, or stimulus given by an individual, namely the management of the SAE Pujon Cooperative, to other individuals, which in this case is the community / farmer members of the cooperative, with information in such a way that the person given the motivation obeys or does what who are motivated critically, rationally, and responsibly;

3) Empathy, is the ability to take or play a role effectively and someone or other people in true condition, as if to feel what other people feel, such as pleasure, pain, difficulty, and happiness. Four is almost like sympathy. The difference is that empathy is more animating or more visible emotionally. An example of empathy is when farmers are concerned about the deterioration in the quality of fresh milk caused by a mixture of water and coconut milk from other farmers in one group. As a result, all milk from the sub collecting point also affected the standard price decline; 
4) Suggestion, is the influence of one's views on others in a certain way, so that the person follows that view / influence without thinking. Suggestions are usually made by people who are authoritative, have great influence, or are well-known in society. However, in the SAE Pujon Cooperative, it is actually carried out by fellow breeders who are members of the Istighozah group. An example of one suggestion is a drug that is expensive, which is an imported product that is considered effective in curing diseases. This assumption is a suggestion that arises due to the high price of drugs and foreign products. ;

5) imitation, is the act or attempt to imitate the actions of others as the ideal character. Imitation tends to be done by someone unconsciously. The first imitation will occur in family socialization;

6) identification, is the tendency or desire in a person to be the same as others. Identification results in a deeper influence than suggestion and imitation because identification is done by someone consciously.

\section{RESEARCH CONCLUSIONS AND RECOMMENDATIONS}

\subsection{Conclusion}

1) Communication and Interaction of Managers / Chairpersons and Managers with Cooperative Members.

By using several symbols or symbols in an interaction in the SAE Pujon cooperative community, there are several goals he wants to achieve, namely as follows:

a. The symbol or symbols is an attempt to influence the socialization process of the community in general and members of the cooperative in particular.

b. The purpose of forming these symbols or symbols is to function as social signs to show a good path towards rural economic development through the Cooperative movement to the community or members.

c. Symbols or symbols that exist in society and have a function to show or simplify the rules that apply to human behavior, especially the cooperative community.

d. These symbols were created as a means of control as well as a form of enlightenment for the future of a society (members of the cooperative), in order to easily understand the economic conditions that are being managed together with the cooperative.

2) Symbolic Interaction of Management / Chairperson of the SAE Pujon Cooperative as a Communication Process.

Based on the explanation of the results of this study, conclusions can be drawn about the existence of symbols in a cooperative society as a means of interaction, namely as follows:

a. Symbol or symbol of communication in a farmer community, members of the SAE Pujon Kopersi, are influenced by culture, community beliefs, their hopes for their future.

b. Community members of the cooperative have a symbol of communication in the process of their interactions with fellow members of the SAE Pujon Cooperative or with the chairman and employees.

c. Symbols or symbols of communication in the process of interaction within the SAE Pujon Cooperative are heavily influenced by beliefs and culture as well as their hopes for the survival of cattle breeders and welfare in the future.

3) Inhibiting and Supporting Factors in Communication and Interaction of Management with Members

a. This internal inhibiting factor resides in the individual himself. Where feelings of disappointment, dissatisfaction generate stress for the community members of the cooperative.It can be concluded that stress is the body's response to demands from within and the environment that exceeds the limits of an individual's ability, causing physical and psychological stress to occur.

b. The external inhibiting factor is the perception of the community members of the cooperative which is not the same as one another.

c. The internal supporting factor is the existence of an internal cooperative policy which is packaged in the form of a Special Regulation (Persus) which is communicated personally. Interpersonal communication that can be said to be effective is very important for members of the organization which can be expected to produce exchange results in information and mutual understanding of one another (Mutual Understanding).

d. The external supporting factor is the existence of a general opinion regarding the social changes in the existence of the SAE Pujon cooperative, in the midst of society. 
4) Efforts to legitimize symbols or symbols with the values of the cooperative community, also aim to build an impression (image) to the community, that the symbols used by the cooperative are symbols that do not conflict with the social values of society. In fact, it is said that the content of these symbols or symbols complement and co-exist with the social values of society.

5) Furthermore, a compromise attitude towards the Cooperative movement creates a new atmosphere in symbols, meaning that these symbols are given a rational nuance, with the hope that the function of the symbol or symbol gets legitimacy from the Cooperative members. The aim is that this symbol can remain in the life practices of the cooperative, in order to maintain its existence and provide a positive message or image for the development of the SAE Pujon Cooperative.

6) Symbols of objects that are provided and used as a medium to communicate the achievement of goals, are social actions carried out by management, employees and members based on conscious and rational considerations and choices.

7) The symbol of the movement that is carried out is an expression of the emotional expression of the soul of what has been done and what has been done. Such as shaking the head, swinging the hands left and right, forward and backward movements, appear to show the same movements due to habits acquired from social processes, without conscious planning.

8) Religiosity in the istighozah event is a form of the depth of religious appreciation of the Pujon people, especially the dairy farmers who are members of the SAE Pujon Cooperative, and their belief in the existence of God Almighty and manifested by obeying all orders and avoiding prohibitions with sincerity of heart.

\subsection{Research Recommendations}

1) Theoretical Implications

Based on the communication aspect, the results of this study strengthen Harold Lasswell's theory of communication, which states that the main components that play a role in the communication process include communicators, messages, media, communicants and the effects of the communication process.

In conveying messages by communicators, this is where there is a process of composing meaning that is prepared so that the communication is more effective. In basic terms, humans communicate through encoding and decoding processes. Encoding is the person who develops and sends messages. As shown the encoder must determine how the message will be received by the audience, and make adjustments so that the message is received the way they want it to be received. Decoding is the person who receives the message and translates the symbols used by the communicator in an area of interaction.

Judging from the way of interacting with the SAE Pujon Cooperative Executive / Chair, the sentence that is often used to command duties cannot be separated from the word "nyuwun tulung". When viewed from the theory of Harnack and Fest (1964), it considers communication as "a process of interaction between people for the purpose of intrapersonal and interpersonal integration" (Rakhmat, 1986: 9) [8]. So the word nyuwun tulung becomes the center of the word that must be coded before it is transmitted through spoken media, to integrate the message of the SAE Pujon cooperative chairman and be accepted by members.

So the point is the similarity between the perceptions of the chairman of the SAE Pujon cooperative with the members' perceptions of the coded message, as stated by Wilbur Schramm that "communication" ends from the idea of discussion and conversation, the understanding of the language or symbols used and the common goal. So it is hoped that if all of these elements are met, it will result in agreement between communication actors regarding the message conveyed.

In terms of Symbolic Interaction Theory, according to the communication dictionary (Effendy. 1989: 184) the definition of interaction is the process of influencing one another in the form of behavior or activities among community members, and the definition of symbolic (Effendy. 1989: 352) is symbolic of something. Meanwhile, one of the basic needs of humans is the need for symbolization or the use of symbols, where humans are the only animals that usually use the symbolic way [16].

Symbolic Interaction according to Effendy (1989: 352) is an idea which states that the essence of social interaction between individuals and between individuals and groups, then between groups and groups in society, is because of communication, a unity of thought where previously in each other those involved take place internalization or kebatinan [16].

The author defines symbolic interaction as anything that is related to the formation of the meaning of an object or symbol or symbol. Both inanimate objects and living things, through a process of communication through verbal messages and nonverbal behavior. The ultimate goal is to interpret the symbol or symbol (object) based on the collective agreement prevailing in a particular area or community group. In this case the Pujon people and in particular the Kop SAE Pujon members.

Verbally, as a manager of a cooperative institution, a manager / chairman of the SAE Pujon Cooperative, in carrying out his duties, is always a determinant for employees and members. In giving "orders" to employees and members. The Chairman of the Cooperative mostly uses the hodgepodge language, namely "Indonesian mixed with Javanese". However, the treatment 
for giving prohibitions to members is mostly using Indonesian. This is done so that the communication process (interaction) runs effectively, because both employees and members are very heterogeneous in knowledge and Indonesian language skills.

Judging from the theory of "Sapir and Whorf", which states that language provides a different network of roads for each society as a result, focusing on certain aspects of reality. In verbal communication, language plays an important role. Verbal communication contains denotative meaning. The media that is often used is language. Because, language is able to translate one's thoughts to others. Through words, they express their feelings, emotions, thoughts, ideas or intentions, convey facts, data and information and explain them, exchange feelings and thoughts, argue with each other, and fight.

Language can also be considered as a verbal coding system (Mulyana, 2005) [6]. Language can be defined as a set of symbols, with rules for combining these symbols, which are used and understood by a community. Symbols or verbal messages are all kinds of symbols that use one or more words.

Rakhmat (1994), defines language functionally and formally. Functionally, language is defined as a shared tool to express ideas [8]. He emphasized being shared, because language can only be understood if there is an agreement among members of the social group to use it. Formally, language is defined as all sentences imaginable, which can be made according to grammatical rules. Every language has rules for how words must be arranged and arranged in order to give meaning.

Thus, it can also be said that the language used by the chairman of the SAE Pujon Koperasi Management when interacting with employees and members is a statement of thought and even a procedure for testing the structure of thinking about something. According to Pinker (1994), it is stated that there is a close relationship between language and consciousness, as in the statement 'we speak intellectually through language'. Through language we know the mentality of other people who express themselves with words (emotions). Humans without language, mentally incomplete [17].

2) Practical Implications

Practical suggestions in this research are as follows:

a. Although the symbolic interaction between the Management / Chairperson and the Management Team and Members of the "SAE Pujon" Cooperative has been going well and smoothly, this symbolic interaction should be maintained properly and even increased so that the existence of the dairy business in the "SAE Pujon" Cooperative can be maintained as a efforts to maintain the harmonization of life of cooperative members and improve their welfare.

b. Given the large role of symbolic interactions in the harmonization of life and community welfare through the presence of the "SAE Pujon" Cooperative, it is hoped that the Management / Chairperson, Managers can increase symbolic interactions with their members and the surrounding community. Language as a symbol of interaction is directed to the Board / Chairperson and Manager to use a series of cool sentences with a choice of words that are easily understood by members. It is also recommended to use the phrase "Seduluran Selawase" as an effort to minimize conflicts that occur at the member level and at the level of the "SAE Pujon" cooperative institution.

c. Considering the success of the "SAE Pujon" Cooperative in its symbolic interaction resulting in a social process and social change in the Pujon sub-district community and harmonization and improvement of community welfare, it is recommended that the government in developing cooperatives adopt the "SAE Pujon" cooperative development pattern.

d. Given that there are still a small number of cooperative members and the Pujon community who have less positive opinions on the success of the "SAE Pujon" cooperative, it is advisable for the Management / Chairperson and Manager to analyze more deeply the activities related to the cooperative's business, especially in applying for dairy credit loans, so that the possibility of business deviation can be avoided. It is also hoped that the Management / Chairperson and Manager will be more effective in implementing the dairy cow business assistance program whose capital is financed by the Savings and Loan Unit at the "SAE Pujon" Cooperative. In addition, it is also suggested to the Management / Chairperson and Manager to continue to broaden the understanding of the Pujon community about the existence of the "SAE Pujon" Cooperative through various media that are easily accessible to the Cooperative, both mass media, electronic media and even spiritual activities such as "Istighosah", so that people who previously have their opinion negative views turn into positive opinions.

\section{REFERENCES}

1. Kotler, Philip. 1995. Marketing Management Analysis, Planning, Implementation, and Usability, Eighth Edition, Salemba Empat, Jakarta.

2. Parasuraman, A., Zeithaml, V.A. and Berry, L.L. (1998), SERVQUAL: A multiple item scale for Measuring consumer perceptions of service quality, Journal of Retaling, vol. 64 No, 1, pp. 12-40. 
International Journal of Advances in Scientific Research and Engineering (ijasre), Vol 7 (2), February -2021

3. Supraticnya, A. 1997. Interpersonal Communication, Psychological Review. Third Print. Yogyakarta: Kanisius.

4. Widjaja, A.W. 2000. Introduction to Communication Studies. Jakarta: Rineka Cipta.

5. Sobur, Alex. 2003. Communication Semiotics, Youth Rosdakarya, PT, Bandung.

6. Mulyana, Deddy. 2005. Communication Studies: An Introduction. Bandung: Youth Rosdakarya.

7. Ali, Muhammad and Mohammad, A. 2004. Developmental Adolescent Psychology, Students. Jakarta: Earth Literacy.

8. Rahmat Kriyantono, Ph D, 2014. Practical Techniques for Communication Research, Kencana Prenada Media, Jakarta.

9. Moleong, Lexy. J. 1991. 2001. Qualitative Research Methods. Bandung: PT Remaja Rosdakarya.

10. Miles and Huberman. 1992. Qualitative data analysis. (translated by Ole: Tjetjep Rohedi Rosidi). Jakarta: University of Indonesia

11. Dawn, Marhaeni. 2009. Communication Science Theory \& Practice. First Edition, Graha Ilmu ,. Yogyakarta.

12. Cangara, Hafied. 2006. Introduction to Communication Studies. Jakarta: PT Raja Grafindo. Homeland.

13. Sarafino. E. P. 1997. Health Psychology: Biosychosocial Interactions. New York: John Wiley \& Sons. Inc.

14. Wursanto. 2005. Fundamentals of Organizational Science. Yogyakarta: Andi.

15. Devito, Joseph A. 2011. Inter-Human Communication. Pamulang-Tangerang. South: Karisma Publishing Group.

16. Effendy, Onong Uchjana. 2000. Science, Theory and Philosophy of Communication. Citra Aditya Bakti, PT, Bandung.

17. Pinker, Steven. 1994. The Language Instict. New York: A Division of Harper Collins Publisher. 